\title{
A Correlative Study of Cardiovascular Response to Sustained Hand Grip in Healthy Young Adults with Fat Free Mass Index
}

\author{
Dr.Aparajita Priyadarshini ${ }^{1}$,Dr.Snigdha Prava Mishra ${ }^{2}$,Dr.Bipin Bihari Pradhan ${ }^{3}$ \\ ${ }^{I}$ Post graduate student, Department of physiology, M.K.C.G Medical college,Berhampur,Odisha. \\ ${ }^{2}$ Associate Professor, Department of physiology, M.K.C.G Medical college,Berhampur,Odisha. \\ ${ }^{3}$ Professor and Head of the department, Department of physiology, M.K.C.G Medical \\ college,Berhampur, Odisha.
}

\begin{abstract}
The cardiovascular changes like increase in heart rate (HR) and mean arterial pressure(MAP) following isometric contraction (sustained hand grip) are mediated largely by the sympathetic nervous system which is activated by both central command to autonomic system and by reflexes arising within the contracting muscle .Body mass index (BMI) has been used since long to asses health and obesity. But BMI has the limitation of not distinguishing between fat and fat free mass. Hence the validity of BMI as an indicator of body fat in cardiovascular risks is recently challenged. So the present study was taken up with an objective to find out the cardiovascular changes during sustained hand grip and their relation with BMI, body fat percentage $(B F \%)$, fat free mass(FFM) and fat free mass index(FFMI).The study included 50 healthy young adults ( 31 male \& 19female) of age group 17-25 yrs. Their height and weight were measured. Basal heart rate and blood pressure were recorded. BF\% was measured by OMRN body fat Monitor. They were subjected to hand grip at $30 \%$ max. Voluntary contraction $(M V C)$ for 3 minutes. HR \& BP were recorded at the end of 3 min . SBP\&MAP showed significant correlation with FFM and FFMI but it was insignificant with BMI.
\end{abstract}

Keywords: Sustained hand grip, Body mass index, Body fat \%, Fat free mass, Fat free mass index.

\section{Introduction:}

The cardiovascular changes like increase in heart rate (HR) and mean arterial pressure(MAP) following isometric contraction (sustained hand grip) are mediated largely by the sympathetic nervous system which is activated by both central command to autonomic system and by reflexes arising within the contracting muscle ${ }^{1}$. Obesity which is considered as major public health problem is also one of the major risk factors for heart diseases and is associated with altered autonomic function giving rise to cardiovascular dysfunction ${ }^{2}$.

Body mass index (BMI) has been used since long to assess health and obesity. But it includes both body fat and fat free mass (chief structural and functional component of the human body). A Person with high BMI due to high fat free mass (FFM) will have better cardiovascular efficiency than a person with high BMI due to high body fat $\%(\mathrm{BF} \%)$. Hence the validity of BMI as an indicator of body fat (BF) in cardiovascular risks is recently challenged. ${ }^{3}$

So the present study was taken up with an objective to find out the cardiovascular changes during sustained hand grip and their relation with BMI, body fat percentage (BF\%), fat free mass(FFM) and fat free mass index(FFMI).

\section{Materials And Methods:}

This prospective study was conducted in the PG Research Lab of Dept. of physiology, MKCG Medical College, Berhampur during the period from Nov. 2011 to Oct. 2012 after due approval from the Institutional Ethics Committee. Study included 50 healthy young adults both male(31) and female(19) within age group of 17 to 25 years. The experimental protocol was explained to all the subjects and written consent was obtained from all of them. The subjects with history of smoking, asthma, any other past or concurrent pulmonary disease and any other systemic disease were excluded from the study. The study was conducted after a minimum of 2 hours of light breakfast. To avoid circadian variation all study were conducted between 10 am to 12 noon.

Body weight was recorded in kilograms on empty bladder and before lunch wearing light weight clothing and bare foot with "Prestige Digital weighing scale". Standing height was recorded using stadiometer to the nearest $0.1 \mathrm{~cm}$. BMI was calculated using Quetlet 's index, BMI $=$ Weight $($ in $\mathrm{Kg}) /$ Height(in meters ${ }^{2}$.

Body fat percentage was measured by "Bioelectric Impedance analysis" technique using OMRON Body Fat Monitor(HBF-306).FFM and FFMI were calculated from BF\% as follows-

$\mathrm{FFM}=(100-\mathrm{BF} \%) / 100 \times$ Weight (in Kg) FFM=FFM/Height (in $\mathrm{m}^{2}$ )

The basal heart rate (HR) and blood pressure (BP) of the study group were recorded by Clarity Med (PMS 320) Cardiac Monitor. Each subject was asked to grip the Med Scale Hand Grip Dynamometer with their dominant 
hand at $30 \%$ of maximum voluntary contraction (MVC) for three minutes. Then HR and BP (both systolic and diastolic) were recorded at the end of 3 mins. MAP was calculated.

The data obtained were analysed using statistical software (Graph Pad Prism version 6). The change in cardiovascular parameters was analysed by paired t-test and their relation with BMI,BF\%,FFM and FFMI was analysed by using correlation and linear regression methods.

\section{Observation And Analysis:}

Mean anthropometric measurements are shown in Table1

TABLE 1.

\begin{tabular}{|l|l|l|}
\hline $\begin{array}{c}\text { Anthropometric } \\
\text { parameters }\end{array}$ & MALE $(\mathrm{n}=31)$ & FEMALE$(\mathrm{n}=19)$ \\
\hline Age in yrs & $19.64 \pm 1.06$ & $19.1 \pm 1.21$ \\
\hline HEIGHT(in cms) & $165.86 \pm 4.68$ & $154.81 \pm 5.83$ \\
\hline WEIGHT(in kg) & $67.27 \pm 9.92$ & $57.36 \pm 8.40$ \\
\hline BMI $\left(\mathrm{Kg} / \mathrm{m}^{2}\right)$ & $24.45 \pm 3.54$ & $23.89 \pm 3.14$ \\
\hline BF\% & $24.47 \pm 5.86$ & $32.23 \pm 4.08$ \\
\hline FFM $(\mathrm{Kg})$ & $50.91 \pm 6.33$ & $38.60 \pm 3.90$ \\
\hline FFMI $\left(\mathrm{Kg} / \mathrm{m}^{2}\right)$ & $18.51 \pm 2.26$ & $16.08 \pm 1.11$ \\
\hline
\end{tabular}

Though in both the groups BMI is within normal range (24.45 in Female, 23.89 in Male),

The $\mathrm{BF} \%$ are in higher range ie 24.47 in male (normal(9-19\%) and 32.23 in female (normal $(21-33 \%)^{4}$.

TABLE 2.

Basal cardiovascular parameters and changes after 3 min of sustained hand grip.

\begin{tabular}{|l|l|l|l|}
\hline PARAMETERS & BASAL & 3 Min & P Value \\
\hline HR(Beats/min) & $76.1 \pm 7.83$ & $112.06 \pm 11.30$ & $<0.0001$ \\
\hline SBP(mm of Hg) & $117.24 \pm 10.47$ & $142.78 \pm 11.32$ & $<0.0001$ \\
\hline DBP(mm of Hg) & $77.28 \pm 7.07$ & $90.86 \pm 13.72$ & $<0.0001$ \\
\hline MAP $(m m$ of $\mathrm{Hg})$ & $90.6 \pm 7.20$ & $108.16 \pm 9.93$ & $<0.0001$ \\
\hline
\end{tabular}

After 3 min of sustained hand grip all the cardiovascular parameters under study (HR, SBP, DBP and MAP) were increased which was statistically highly significant $(\mathrm{p}<0.01$ significant).

Heart rate after 3 minutes of sustained hand grip was statistically analysed for any correlation with BMI, BF\%, FFM and FFMI but no significant correlation was observed .

TABLE3.

correlation of SBP with BMI,BF\%,FFM and FFMI.

\begin{tabular}{|c|c|c|c|c|}
\hline CORRELATION & $\begin{array}{c}3 \text { min } \\
\text { SBP vs BMI }\end{array}$ & $\begin{array}{c}3 \mathrm{~min} \\
\mathrm{SBPvsBF} \%\end{array}$ & $\begin{array}{c}3 \text { min } \\
\text { SBP } \text { vs FFM }\end{array}$ & $\begin{array}{c}3 \min \\
\text { SBP vs FFMI }\end{array}$ \\
\hline \multicolumn{5}{|l|}{ Person $r$} \\
\hline $\mathrm{r}$ & 0.1711 & -0.1880 & 0.4954 & 0.3825 \\
\hline $95 \%$ confidence level & -0.1127 to 0.4921 & $\begin{array}{cc}-0.4432 & \text { to } \\
0.09540 & \end{array}$ & 0.2518 to 0.6801 & 0.1165 to 0.5973 \\
\hline R square & 0.02928 & 0.03534 & 0.2455 & 0.1463 \\
\hline \multicolumn{5}{|l|}{$\mathrm{P}$ value } \\
\hline $\mathrm{P}$ (two tailed) & 0.2348 & 0.1911 & 0.0003 & 0.0061 \\
\hline $\mathrm{P}$ value summary & ns & ns & $* * *$ & $* *$ \\
\hline Significant? & No & No & Yes & Yes \\
\hline
\end{tabular}

When SBP at 3 mins was correlated with the BMI,BF\%,FFM and FFMI, no significant correlation of SBP was observed with BMI or BF\% but it was highly significant with FFMI and very highly significant with FFM.

However, no significant correlation was observed with DBP.

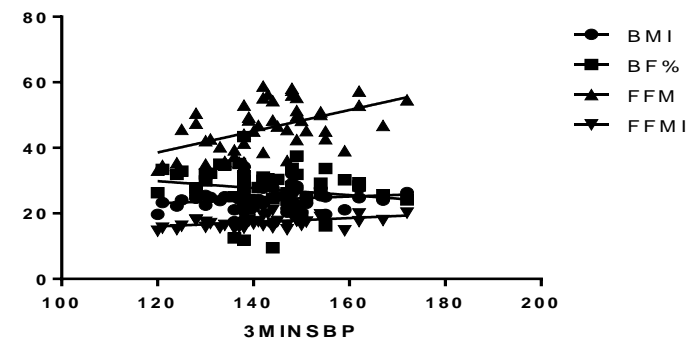

Graph 1.Correlation of 3 min SBP with BMI,BF\%,FFM and FFMI. 
TABLE 4

Correlation of MAP with BMI,BF\%,FFM and FFMI.

\begin{tabular}{|c|c|c|c|c|}
\hline CORRELATION & $\begin{array}{l}3 \text { min } \\
\text { MAP vs BMI }\end{array}$ & $\begin{array}{l}3 \min \\
\text { MAP vs BF\% }\end{array}$ & $\begin{array}{l}3 \text { min } \\
\text { MAP vs FFM }\end{array}$ & $\begin{array}{l}3 \text { min } \\
\text { MAP vs FFMI }\end{array}$ \\
\hline \multicolumn{5}{|l|}{ Person $r$} \\
\hline $\mathrm{r}$ & 0.2369 & -0.1070 & 0.3965 & 0.3909 \\
\hline $\begin{array}{ll}95 \% & \text { confidence } \\
\text { level } & \end{array}$ & -0.04440 to 0.4835 & -0.3743 to 0.1767 & 0.1327 to 0.6078 & $\begin{array}{l}0.1263 \\
0.6036\end{array}$ \\
\hline R square & 0.05614 & 0.01145 & 0.1572 & 0.1528 \\
\hline \multicolumn{5}{|l|}{$\mathrm{P}$ value } \\
\hline $\mathrm{P}$ (two tailed) & 0.0976 & 0.4595 & 0.0044 & 0.0050 \\
\hline $\mathrm{P}$ value summary & ns & ns & $* *$ & $* *$ \\
\hline Significant? & No & No & Yes & Yes \\
\hline
\end{tabular}

While MAP showed insignificant correlation with BMI and BF\%, its correlation with FFM and FFMI was highly significant.

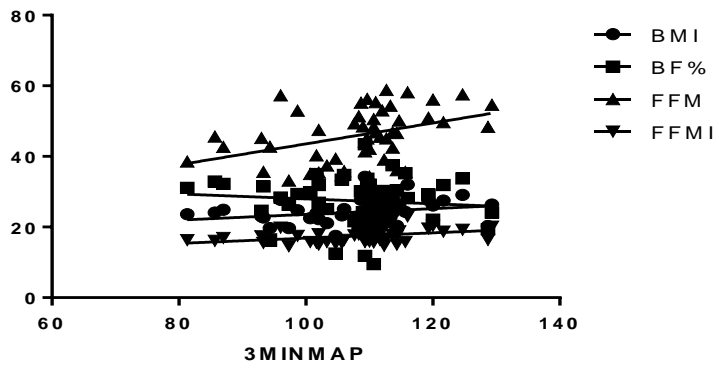

Graph 2: correlation of MAP with BMI,BF\%,FFM \&FFMI.

\section{Discussion}

In our study cardiovascular parameters like HR, SBP, DBP and MAP were significantly increased following isometric contraction. Similar changes were observed by A R Lind et al ${ }^{5}$,E Cheneau et al ${ }^{6}$, S Sucharita et $\mathrm{al}^{7}$ and G M Goodwin et al ${ }^{8}$. We found out that SBP and MAP correlated better with FFM and FFMI than BMI and BF\%.

The fat free mass which consists of muscle mass, bone and water is considered the chief structural and functional component of body and FFMI includes the height/stature of body. FFMI= (FFM/height in $\left.\mathrm{mt}^{2}\right)$. Two Mechanisms could be responsible for the role of muscle mass in the cardiovascular response following isometric contraction ${ }^{910}$

1.Central command theory; It involves activation of higher brain centres on the volition and initiation of muscular contraction. Greater the no of motor units activated to accomplish a particular contraction ,greater the integration of such a signal by central controlling neurons, the greater will be the central command input to the brainstem cardiovascular centre and therefore the greater the cardiovascular response during isometric exercise.

2. Exercise pressor reflex theory: suggests that there is a reflex stimulus originating in nerve endings in the contracting muscles. Thus during sustained isometric contraction the greater the number of motor units activated, greater the activation of afferent nerve fibres to the contacting muscle suggesting increase cardiovascular response is related to muscle mass. This signifies the important role played by FFM and FFMI on cardiovascular changes following isometric contraction. Similar findings were observed by M Hulens et al. ${ }^{11}$

\section{Conclusion:}

Our study shows SBP \& MAP are positively correlated with FFM and FFMI (Highly significant) \& negatively correlated with BF\%. The correlation with BMI is insignificant. Again our study supports the fact that muscle mass and strength has positive effect on cardiovascular function .So the cardiovascular risk assessment by BMI alone can be misleading and better parameters like BF\%, FFM, FFMI can be effectively used. The cardiovascular efficiency can be improved by increasing the fat free mass through regular activities like aerobic exercise. 


\section{References:}

[1]. Leonard,B.,Mitcel,J. H.,Mizunu,M.,Rube,N.,Saltin,B. \& Secher,N.H. Partial neuromuscular blockade and cardiovascular response to static exercise in man. .Journal of physiology, 1985; 359:365-379.

[2]. Vanderlei,LCM.,Pastre, CM.,Godoy,MF. et al .Analysis of cardiac autonomic modulation in obese and eutropic children. Clinics.2010;65(8):789-792.

[3]. Muralidhar ,D.V.\& Ramesh Bhat M. Futrex 5000-A over estimates body fat in young Indians of different body mass index. The journal of physiological sciences. 2006;19(3):31-37

[4]. Gallagher et al.Approprite Body Mass index for Asian population \& its implication for policy and intervention strategies. American journal clinical nutrition;2000;72:694-701

[5]. Lind,A.R. \& McNicol, G.w. Circulatory response to sustained hand grip contractions performed during other exercise, both rhythmic and static. Journal of physiology.1967a;192:595-607.

[6]. Cheneau, e.,Cadi,F.,Bensouda,C.,Charasse,A.,Ritz ,B. \&Aupetit,JF. Studyof blood pressure, hemodynamic, ventilator and metabolic response to isometric exercise.Arch Mal Coer Vaiss. 2001;94:863-868

[7]. Sucharita, S.,Bharati, A.V.\& Mario V. Effect of age and nutritional status on heart rate response to cough and maximal hand grip.Indian Journal of Physiol Pharmacol. 2004;48(1):106-110.

[8]. Goodwin, G. M.,McCloskey \& MitchelJ. H. Cardiovascular and respiratory responses to changes in central command during isometric exercise at constant muscle tension. Journal of physiology.1972;226:173-190.

[9]. JoseMGalvez,JuanP. Alonso,Luis A. Sangrador and Gonzalo Navarro,Effect of muscle mass and intensity of isometric contraction on heart rate; J Appl physiol 88:487-492,2000

[10]. F Iellamo,M.Massaro,G.Raimondi,G Peruzzi \&J.M.Legramante.Role of muscular factors in cardiorespiratory responses to static exercise:contribution of reflex mechanisms

[11]. Hulens,M.,Vansant, G.,Lysens R., Claessens,A L.,Mules E. \&Brumagne, S. Study of differences in peripheral muscle strength of lean versus obese women: an allometric approach. International Journal of Obesity. 2001;25(5):676-681. 